1 Supplementary Material for 'Estimation of Reactive Inorganic Iodine Fluxes in the

2 Indian and Southern Ocean Marine Boundary Layer'

3 Swaleha Inamdar ${ }^{1,2}$, Liselotte Tinel $^{3}$, Rosie Chance ${ }^{3}$, Lucy Carpenter ${ }^{3}$, P. Sabu ${ }^{4}$, Racheal

4 Chacko $^{4}$, Sarat C. Tripathy ${ }^{4}$, Anvita U. Kerkar ${ }^{4}$, Alok K. Sinha ${ }^{4}$, P. V. Bhaskar ${ }^{4}$, Amit

5 Sarkar ${ }^{4,5}$, Rajdeep Roy ${ }^{6}$, Tomas Sherwen ${ }^{3,7}$, Carlos Cuevas ${ }^{8}$, Alfonso Saiz-Lopez ${ }^{8}$, Kirpa

$6 \operatorname{Ram}^{2}$ and Anoop S. Mahajan ${ }^{1 *}$

$7{ }^{1}$ Centre for Climate Change Research, Indian Institute of Tropical Meteorology, Dr Homi

8 Bhabha Road, Pashan, Pune, 411 008, India

$9 \quad{ }^{2}$ Institute of Environment and Sustainable Development, Banaras Hindu University, Varanasi, 221005, India

${ }^{3}$ Wolfson Atmospheric Chemistry Laboratories, Department of Chemistry, University of 12 York, YO10 5DD, UK

${ }^{4}$ National Centre for Polar and Ocean Research, Goa, 403 804, India

${ }^{5}$ Environment and Life Sciences Research Centre, Kuwait Institute for Scientific Research

${ }^{6}$ National Remote Sensing Centre, Department of Space Government of India Balanagar, Hyderabad, 500 037, India

${ }^{7}$ National Centre for Atmospheric Science, University of York, York YO10 5DD, UK Rocasolano, CSIC, Madrid, Spain.

21 * corresponding author: Anoop S. Mahajan (anoop@tropmet.res.in); phone: +91 202590 
1. Abbreviations used in the text:

25

ISOE-8 $\quad 8^{\text {th }}$ Indian Southern Ocean Expedition

26 IIOE-2

$2^{\text {nd }}$ International Indian Ocean Expedition

27

ISOE-9

$9^{\text {th }}$ Indian Southern Ocean Expedition

SK-333

Sagar Kanya-333 expedition in the south Indian Ocean

BoBBLE

Bay of Bengal Boundary Layer Experiments

30

Chl- $a$

Chlorophyll- $a$

HYbrid Single-Particle Lagrangian Integrated Trajectory (HYSPLIT) model (Rolph et al., 2017; Stein et al., 2015)

Differential slant column density(ies)

\section{Multiple linear regression analysis}

A region-specific parameterisation tool for estimating sea surface iodide concentration was developed following the (Chance et al., 2014) method. Observations for SSI concentrations from ISOE-9, SK-333 and BoBBLE were used for the multiple linear regression analysis against various atmospheric and oceanic parameters. SST data used for linear regression analysis was recorded during ISOE-9 using a bucket thermometer at an interval of 6 hours accounting for a change of approximately 1 degree in the latitudinal track of the ship and simultaneously during each seawater iodide sampling. Seawater samples collected during ISOE-9 at the same interval as the recorded SST were used for salinity retrievals using the AUTOSAL salinometer. For the SK-333 and BoBBLE expeditions most of the samples were collected from the CTD casts and some (4 data points) were underway samples in case of 
BoBBLE expedition. The MLD climatological monthly mean computed from climatological monthly mean profiles of potential temperature and potential density based on three different criteria was obtained using the World Ocean Atlas (Monterey and Levitus, 1997). That being; a temperature change from the ocean surface of 0.5 degree Celsius $\left(\mathrm{MLD}_{\mathrm{pt}}\right)$, a density change from the ocean surface of 0.125 (sigma units) $\left(\mathrm{MLD}_{\mathrm{pd}}\right)$, and a variable density change from the ocean surface corresponding to a temperature change of 0.5 degree Celsius $\left(\mathrm{MLD}_{\mathrm{vd}}\right)$ (Monterey and Levitus, 1997). All three climatological monthly mean MLD data types $\left(\mathrm{MLD}_{\mathrm{pd}}, \mathrm{MLD} \mathrm{pt}\right.$, and $\left.\mathrm{MLD}_{\mathrm{vd}}\right)$ were used for linear regression with measured iodide concentration. The climatological monthly mean of sea surface nitrate concentrations for ISOE-9 was also obtained from the World Ocean Atlas 2013, version 2 (Garcia et al., 2013). Chl- $a$ data for ISOE-9 was obtained from pigment analysis during ISOE-9.

\section{Dataset used for SSI estimation}

For estimating the SSI concentrations for all campaigns (ISOE-8, IIOE-2, and ISOE-9) using parameterisation methods in Eq. (1) to (5), the oceanic parameters were obtained from the observations during individual campaigns. Missing data was substituted with available data, as in the case of IIOE-2 campaign. For this campaign, salinity data was obtained from the World Ocean Atlas 2013, version 2 (Zweng et al., 2013). Also, chl-a data for IIOE-2 was obtained from level 3 daily and 8-day products of Aqua MODIS satellite (NASA-GSFC, 2017). Similarly, sea surface nitrate concentrations and MLD for all the campaigns were obtained from World Ocean Atlas (Garcia et al., 2013; Monterey and Levitus, 1997).

\section{Parameterisation for SSI estimation}

Chance et al. (2014) developed two versions of empirical relationship for SSI estimation. The first one is given in the main text (Eq. 1). For the regional specific modification (Eq. 2 and 3), each of the oceanic parameters was obtained for the same location (SST, salinity, chl-a) as 
the measured SSI concentrations from ISOE-9, SK-333 and BoBBLE. Likewise, monthly climatological datasets were obtained for MLD and nitrate with a one-degree spatial resolution, as described in the previous section. The regression analysis for region-specific modification was initially divided in three sections - first for the all the SSI observations including the Indian Ocean and the Southern Ocean (ISOE-9, SK-333, and BoBBLE). The second only for the Southern Ocean region (ISOE-9) and lastly only the Indian Ocean region (SK-333 and BoBBLE). The third scenario was rejected due to poor and insignificant coefficient of determination values $\left(\mathrm{R}^{2}\right)$ for individual parameters. The resulting parameterisation too was unable to fit the observations with predicted values for the Indian Ocean region. In this case, SST and latitude were the only parameters that correlated positively to the SSI. The first and second scenario resulting in parametrisation denoted by Eq. (2) and Eq. (3) respectively is given in the main text. A list of $\mathrm{R}^{2}$, slope, intercept and significance of all parameters for linear regression with observed iodide concentration is provided in Table S1. A combination similar to the Chance parameterisation given in Eq. (2) gave maximum $\mathrm{R}^{2}$ value of $0.794(\mathrm{~N}=128)$ for the Indian Ocean and the Southern Ocean region. In this equation, all parameters are significant except for salinity and nitrate concentration. Removal of any one of these insignificant parameters did not make the other significant. The coefficient for this equation (Eq. 2) also remained insignificant with high error value $(22 \pm 137)$. The combination of $\mathrm{SST}^{2}$, latitude, nitrate and salinity resulted in a maximum $\mathrm{R}^{2}=0.86(\mathrm{~N}=110)$ for the dependent variable [iodide] in Eq. (3). The inclusion of $\mathrm{MLD}_{\mathrm{pt}}$ (with highest $\mathrm{R}^{2}$ for MLD) increased the $\mathrm{R}^{2}$ slightly but had a non-uniform distribution of the residuals and was thus excluded. Similarly, the addition of chl- $a$ to the equation did not change the $\mathrm{R}^{2}$ significantly, and thus chl- $a$ was removed from the final equation. SSI concentration estimated using the logarithmic parameterisation by Chance et al. (2014) was very high in comparison to the measured SSI concentration from ISOE-9. The 
$\ln$ [iodide] equation estimated SSI concentrations of $\sim 500 \mathrm{nM}$ in the Indian Ocean region which is very high compared to global observations of SSI in the Indian Ocean (Chance et al., 2014, Chance et al., 2019) and in comparison to the observations from SK-333 and BoBBLE for the South Indian Ocean. Therefore, we excluded the logarithmic parametrization for this study and suggest that the $\ln [$ iodide] parametrization is not adequate for SSI estimation.

\section{References}

Chance, R., Baker, A. R., Carpenter, L. and Jickells, T. D.: The distribution of iodide at the sea surface, Environ. Sci. Process. Impacts, 16(8), 1841-1859, doi:10.1039/C4EM00139G, 2014.

Garcia, H. E., Locarnini, R. A., Boyer, T. P., Antonov, J. I., Baranova, O. K., Zweng, M. M., Reagan, J. R. and Johnson, D. R.: WORLD OCEAN ATLAS 2013 Volume 4: Dissolved Inorganic Nutrients (phosphate, nitrate, silicate), NOAA Atlas NESDIS 76., 2013.

Monterey, G. and Levitus, S.: Seasonal Variability of Mixed Layer Depth for the World Ocean. [online] Available from: http://www.nodc.noaa.gov, 1997.

NASA-GSFC: Ocean Color Web. [online] Available from: https://oceancolor.gsfc.nasa.gov/, 2017.

Rolph, G., Stein, A. and Stunder, B.: Real-time Environmental Applications and Display sYstem: READY, Environ. Model. Softw., 95, 210-228, doi:10.1016/j.envsoft.2017.06.025, 2017.

Stein, A. F., Draxler, R. R., Rolph, G. D., Stunder, B. J. B., Cohen, M. D. and Ngan, F.: Noaa's hysplit atmospheric transport and dispersion modeling system, Bull. Am. Meteorol. Soc., 96(12), 2059-2077, doi:10.1175/BAMS-D-14-00110.1, 2015.

Zweng, M. M., Reagan, J. R., Antonov, J. I., Locarnini, R. A., Mishonov, A. V., Boyer, T. P., 
117 Garcia, H. E., Baranova, O. K., Johnson, D. R., Seidov, D. and Biddle, M. M.: WORLD

118 OCEAN ATLAS 2013 Volume 2: Salinity. [online] Available from:

119 http://www.nodc.noaa.gov/OC5/indprod.html, 2013.

120

6. Figures

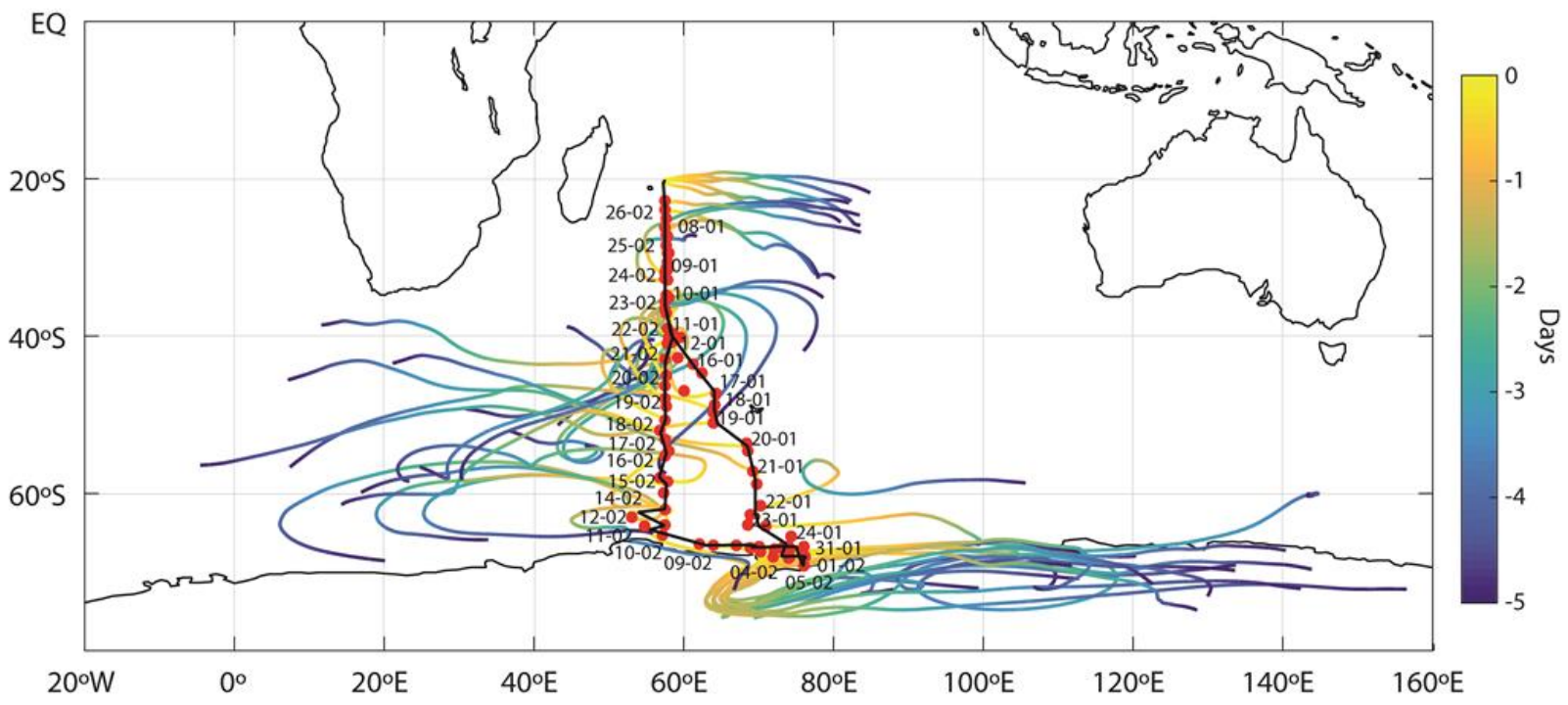

Figure S1: Map of the south Indian Ocean and the Southern Ocean showing the cruise track (black line) for the ISOE-9 campaign. Along the cruise track 5-days backward wind trajectories (HYSPLIT) of the air masses arriving the locations at noon each day of the ISOE-9 expedition. Sea surface iodide sampling locations marked in red circles along with the date of sampling. 
Latitude

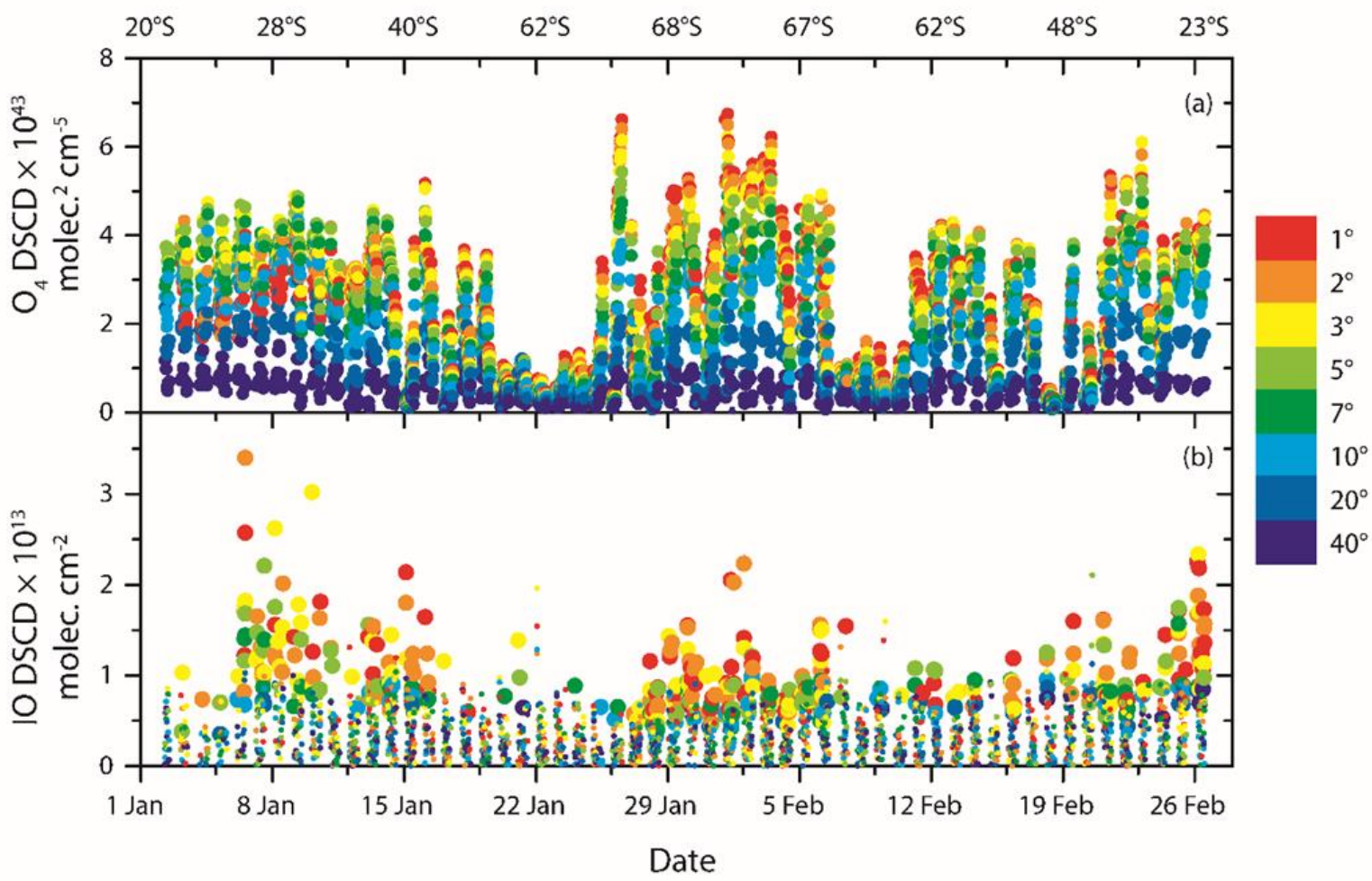

128 Figure S2: Timeline of the $\mathrm{O}_{4}$ and IO DSCDs observed during the ISOE-9 expedition.

129 The top scale indicates corresponding latitudes for the dates, and colour code represents

130 the elevation angle $\left({ }^{\circ}\right)$ for each scan. Smaller circles indicate DSCDs below $\sigma$ detection

131 limit for IO and $2 \sigma$ in case of $\mathrm{O}_{4}$; bigger circles indicate DSCDs above the detection

132 limit respectively. 

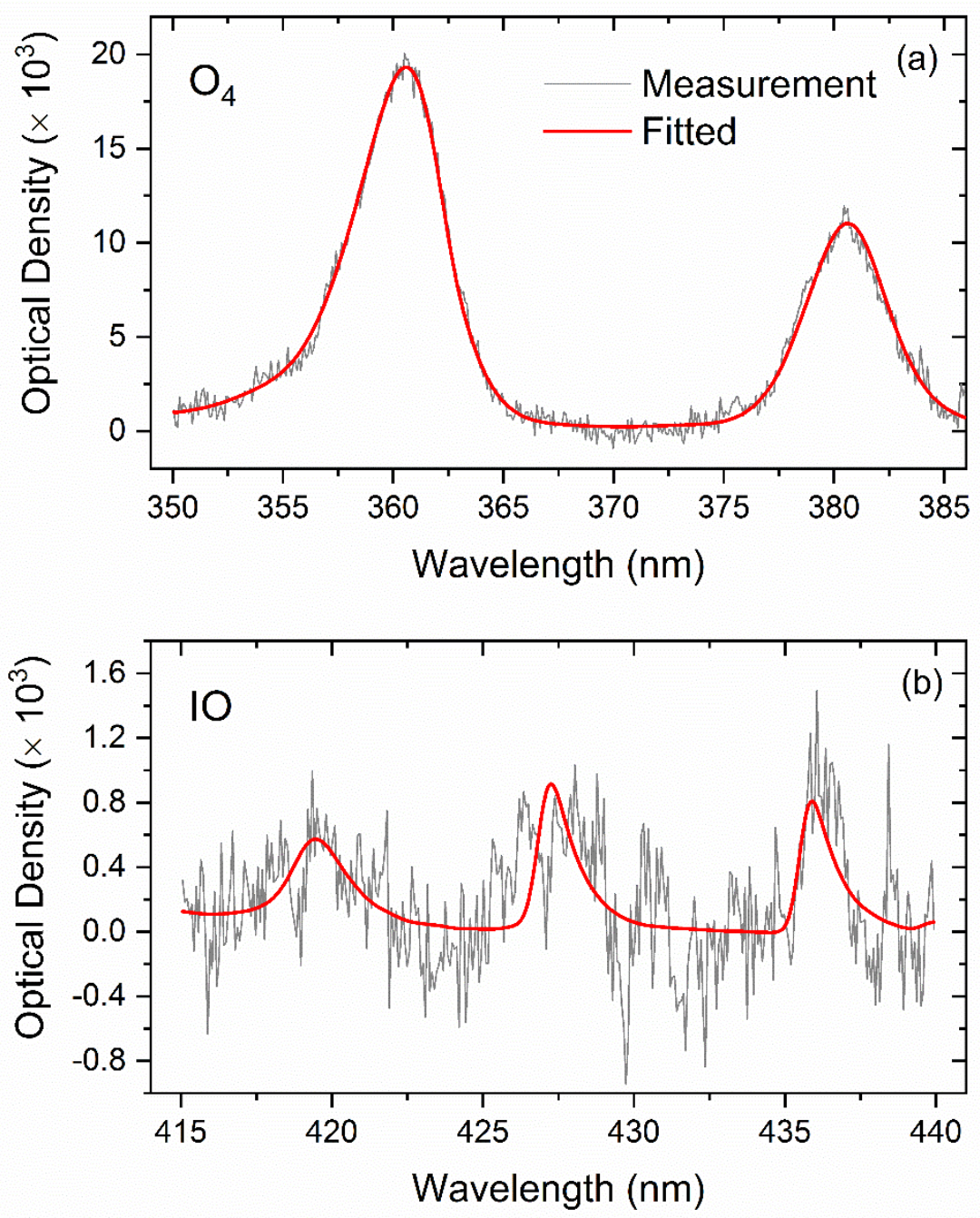

134 Figure S3: An example of typical spectral fit for $\mathrm{O}_{4}$ (a) and IO (b) during the ISOE-9 135 expedition. These spectral fits were taken on 26 February 2017 at 15:35 (local time), for solar zenith angle $69.5^{\circ}$ and $1^{\circ}$ elevation angle. These fits retrieved $\mathrm{O}_{4}$ slant column

137 density of $(4.35 \pm 0.035) \times 10^{43}$ molecules $\mathrm{cm}^{-2}$ and $(2.24 \pm 0.36) \times 10^{13}$ molecules $\mathrm{cm}^{-2}$ with 138 residual optical density (root mean square) of $3.2 \times 10^{-4}$ and $5.5 \times 10^{-4}$ respectively. 


\begin{tabular}{|c|c|c|c|c|}
\hline Parameter & $\mathbf{R}^{2}$ & Slope (m) & Intercept (C) & $p<5 \% ?(p)$ \\
\hline \multirow{2}{*}{ SST } & 0.64 & $4.26 \pm 0.29$ & $31 \pm 4.77$ & Yes (0) \\
\hline & 0.62 & $4.03 \pm 0.304$ & $32.2 \pm 4.17$ & $\operatorname{Yes}(0)$ \\
\hline \multirow{2}{*}{ 1/SST $\left(\mathbf{K}^{-1}\right)$} & 0.62 & $-345781 \pm 23910$ & $1297 \pm 83.9$ & Yes $(0)$ \\
\hline & 0.59 & $-322918 \pm 25302$ & $1215 \pm 89.5$ & $\operatorname{Yes}(0)$ \\
\hline \multirow{2}{*}{$\mathrm{SST}^{2}$} & 0.73 & $0.16 \pm 0.0085$ & $41.1 \pm 3.6$ & Yes (0) \\
\hline & 0.79 & $0.18 \pm 0.01$ & $39.2 \pm 2.7$ & $\operatorname{Yes}(0)$ \\
\hline \multirow{2}{*}{ NO3 } & 0.42 & $-3.24 \pm 0.34$ & $125 \pm 5.7$ & Yes $(0)$ \\
\hline & 0.39 & $-2.63 \pm 0.32$ & $110.6 \pm 5.8$ & Yes $\left(3.06 \times 10^{-13}\right)$ \\
\hline \multirow{2}{*}{ |Latitude| } & 0.55 & $-2.1 \pm 0.17$ & $178.3 \pm 8.3$ & Yes $(0)$ \\
\hline & 0.52 & $-2.43 \pm 0.22$ & $196.1 \pm 11.7$ & $\operatorname{Yes}(0)$ \\
\hline \multirow{2}{*}{$\begin{array}{l}\text { Monthly } \\
\text { MLD }_{\text {pt }}\end{array}$} & 0.17 & $-1.1 \pm 0.22$ & $125 \pm 9.2$ & Yes $\left(1.2 \times 10^{-6}\right)$ \\
\hline & 0.08 & $-0.63 \pm 0.21$ & $97.6 \pm 9.4$ & Yes $(0.003)$ \\
\hline \multirow{2}{*}{$\begin{array}{l}\text { Monthly } \\
\text { MLD }_{\mathrm{vd}}\end{array}$} & 0.04 & $-0.48 \pm 0.2$ & $98 \pm 8$ & Yes $(0.03)$ \\
\hline & 0.003 & $-0.11 \pm 0.19$ & $75.9 \pm 7.5$ & No $(0.56)$ \\
\hline \multirow{2}{*}{$\begin{array}{l}\text { Monthly } \\
\text { MLD }_{\text {pd }}\end{array}$} & 0.12 & $-0.67 \pm 0.16$ & $110 \pm 7.8$ & Yes $\left(5.2 \times 10^{-5}\right)$ \\
\hline & 0.05 & $-0.35 \pm 0.15$ & $87.1 \pm 7.7$ & Yes $(0.02)$ \\
\hline \multirow{2}{*}{ Salinity } & 0.08 & $16 \pm 4.8$ & $-468 \pm 165$ & Yes $(0.001)$ \\
\hline & 0.23 & $21.8 \pm 3.8$ & $-675 \pm 130$ & $\operatorname{Yes}\left(8 \times 10^{-8}\right)$ \\
\hline \multirow{2}{*}{$\begin{array}{c}\text { Chlorophyll - } \\
a\end{array}$} & 0.025 & $-37 \pm 26$ & $84 \pm 8.6$ & No (0.16) \\
\hline & 0.002 & $-7 \pm 20$ & $62 \pm 7$ & No (0.73) \\
\hline
\end{tabular}

Table S1: Linear regression analysis results for each parameter against field observations of sea surface iodide for paramterisation Eq. (2) in standard font and Eq. (3) in italics. $R^{2}$ represents the coefficient of determination (COD); the last column is a check for statistical significance at $5 \%$ with the p-value in parenthesis. 